\title{
Bounded Innovation Management: Mapping the Patterns of Innovation in a Small Software Development Organization
}

\author{
Kay Fielden and Pam Malcolm \\ Unitec Institute of Technology, New Zealand \\ kfielden@unitec.ac.nz, pmalcolm@unitec.ac.nz
}

\begin{abstract}
In this paper, the second draft of a new model (Bounded Innovation Management Model, BIMM) based in part on systems thinking principles, is presented to contribute to the research being conducted in mapping patterns of innovation. This is an exploratory study in the application of BIMM to a small innovative software development company in New Zealand. The eight constructs of BIMM (structure, communication, control, emergence, role, incentive, outcome and whole system) are applied to individual employees' responses in order to gain insights into innovative pattern mapping within the company. From analyzing the data from these individual responses within this company it has been discovered that: (i) evolutionary innovation patterns oscillate about and are contained by, the bounds that are in place through management practices; (ii) revolutionary patterns of innovation tend to operate outside such bounds and oscillate in the surrounding space; (iii) creative patterns tend to be stifled if completely contained within management bounds; and (iv) employees' perceived mappings of patterns of innovation may vary from the actual patterns within an organization.
\end{abstract}

Keywords: Patterns of Innovation, Software Development Organization

\section{Introduction}

Creativity is an important ingredient in the production of new software solutions. In this research project, the patterns of innovation followed by a small innovative software development company (Organization X) in New Zealand to proceed developing new ideas were investigated. Capturing new ideas, both within and outside of the organization, was regarded by the managing director interviewed as vital to remain competitive and to meet budget requirements. The small organization upon which this case study is based has been in operation for ten years. The concept for the development of the innovative software was developed between 1995 and 2000. In 2001 a joint venture partnership was set up with initially 20 partners. This has since grown to more than 120 joint venture partners. At the same time as the software was being developed and tested, strategic

Material published as part of this journal, either on-line or in print, is copyrighted by the Informing Science Institute. Permission to make digital or paper copy of part or all of these works for personal or classroom use is granted without fee provided that the copies are not made or distributed for profit or commercial advantage AND that copies 1) bear this notice in full and 2) give the full citation on the first page. It is permissible to abstract these works so long as credit is given. To copy in all other cases or to republish or to post on a server or to redistribute to lists requires specific permission and payment of a fee. Contact Publisher@InformingScience.org to request redistribution permission. business plans were put in place to bring products to market. In 2002 the relationship with the University was formed with involvement from an academic adviser who performed both a fatal flaw examination and a proof of concept for the software. The University also provided final semester undergraduate students who developed a multimedia application to demonstrate proof of con- 
cept as a demonstration tool to potential investors and business partners. The organization is funded by joint venture capital and Technology in Industry Fellowships from the New Zealand Foundation for Research Science and Technology. In 2003 the first secure laboratory was constructed at the University and another team of University students created key software elements for the products. A Memorandum of Understanding was signed with the University in 2003. Work began on the preparation of a patent for the software and this was finalized both in New Zealand and in the US in 2005. The Foundation for Research Science and Technology continue to support the work being done by partially funding students' work after completion of their undergraduate degrees. Since the study began with only four paid employees, the work-force has grown to 17 part-time or full-time workers. When the data for this paper was gathered there were only four employees: the managing director, the software developer, the marketing and sales officer, and the joint venture officer.

The theoretical framework emerging from the data is a novel approach to illustrating different patterns of innovation. This model is situated within the realm of core systems principles, (Checkland, 1984), but does not rely on other general systems theory models. The model also has the four constructs of role, incentive, outcome and whole system.

The structure of the paper is as follows: first this new model - the Bounded Innovative Management Model (BIMM) - is described; a literature review investigating creativity and innovation within organizations is presented; the case study approach for this paper is discussed; a discussion of the organization with its individual staff BIMM pictograms is described; followed by findings, discussion and conclusions.

\section{Literature Review}

The literature was searched for definitions of creativity (McIntyre, Higgins, \& Couger, 1993; Oldham \& Cummings, 1996; Peterson, 2002), and innovation (Bartle, 2002; Jones \& Myers, 2001). Existing theories relating creativity to innovation (Bean, 2002; Jones \& Myers, 2001; Kelly, 1999; Rogers, 1995) are also considered. Requirements for innovation (Amabile, 1997; Dewett, 2003; Houtz et al., 2003; Isaksen \& Lauer, 2003; Maturana \& Varela, 1998; Ornstein, 1991; Peterson, 2002; PriceWaterhouseCoopers, 2003; Research, 2003) including incubation time, communication lines, organizational reporting lines, intuition, mental flexibility, freedom to make mistakes and passion are amply discussed within the literature. Dahlberg, Mallat and Oorni (2003), Davis (1989) and Lu, Liu, Yu, and Yao (2002) all explore the relationship between trust and innovation. Organizational concepts including management styles (Goodman, 2000; Lapierre \& Giroux, 2003; MacMillan \& McGrath, 2004; PriceWaterhouseCoopers, 2003); motivation in organizations (Amabile, 1997; McIntyre et al., 1993; PriceWaterhouseCoopers, 2003); organizational culture (Amabile, 1997; Bean, 2002; Cooper, 2000; Patterson, 2001; Peterson, 2002); and organizational structure (Bartle, 2002; Boulding, 1989; Cooper, 2000; Davis-Havill, 2004; Hogarth-Scott \& Parkinson, 1994) are also reviewed from the literature. The relationship between core systems concepts (Checkland, 1984) and innovation is discussed as well as whole systems concepts with respect to soft systems (Checkland \& Scholes, 1990). The literature review concludes with a call for further research (Fichman, 2004; Galliers \& Meadows, 2003; Glenn \& Gordon, 2000; Lapierre \& Giroux, 2003; Maloney, 2002; Marc Edwards, 2000; McIntyre et al., 1993; Peterson, 2002).

Whilst creativity from an aesthetic sense is well defined, the literature on the role of creativity in information technology has not been so well defined. Creativity has been studied within many disciplines without consensus on one defining notion. McIntyre, Higgins and Couger (1993) state that: "the subject of creativity is a neglected area in the literature on information systems" ( $\mathrm{p}$. 377). McIntyre, Higgins and Couger define creativity and the innovations that arise from creative acts as those that demonstrate radical newness in situations where the initial problem situation 
was ill-defined. They also embrace the idea of recombination of known factors to produce something new. Oldham and Cummings (1996) stated that creativity is "useful novelty" (p. 610) novelty that can be applied and add value to an organization's products and services. Creativity includes the generation of ideas, alternatives and possibilities. Peterson (2002) also suggests that both originality and purpose are required for a product to be judged as creative. Unique products with no purpose are judged as having no value.

In New Zealand much emphasis has been placed on providing appropriate governmental infrastructure to nurture innovation via technology research grants, particularly grants for industry. Bartle (2002) defines innovation as opportunistic, non-linear and dynamic, involving the process of extracting value from ideas. Jones and Myers (2001) in considering the adoption and diffusion of information systems innovations state that an innovation is an idea, practice or object that is perceived as new.

Jones and Myers (2001) consider three theories of information systems innovation: (i) the "stages model" (Rogers, 1995); (ii) the Decision Episode Framework (DEF); and (iii) Technological Frameworks. Each model takes a different perspective from linear (the stages model), decision episodes within a network of interrelationships (DEF) to the perceptions of various groups within an organization and the alignment of their technological frameworks. They believe that no one theory is complete and can explain on its own what happened in tracing innovation in any one case. Each theory has its own strengths and contributes to an understanding of the entire innovation adoption process in information systems. Kelly (1999) resorts to complexity theory in an endeavor to understand innovation with human complex adaptive systems that exist within an organization. He states that mechanistic thinking is not sufficient and that complex adaptive systems offer more robust capabilities in accommodating the variety that exists when innovation in organizations is considered. Bean (2002) argues for a model to manage innovation. He is of the opinion that a model allows the situation to be seen more clearly and assists in the understanding of how an innovation functions, is directed and supported.

A complex balance of factors has been identified that are necessary for innovation to occur. These factors include: time to innovate (including incubation time) (Dewett, 2003; Ornstein, 1991) intrinsic motivation (Amabile, 1997; Dewett, 2003; Ornstein, 1991); clear lines of communication between management and staff (Dewett, 2003); cooperation across and between organizational reporting lines (PriceWaterhouseCoopers, 2003); an intuitive personality (Houtz et al., 2003; Isaksen \& Lauer, 2003); mental flexibility (Maturana \& Varela, 1998); passion, freedom to make choices and freedom to make mistakes (Peterson, 2002) and celebration of success (Research, 2003).

$\mathrm{Lu}, \mathrm{Liu}, \mathrm{Yu}$, and Yao (2002) suggest that trust is a complex social phenomenon that reflects numerous ways of interacting between people and technology. These aspects include: technological, behavioral, social and psychological as well as organizational factors. Dahlberg, Mallat and Oorni (2003) in describing their trust-enhanced Technology Acceptance Model (TAM) describe two factors they believe were missing from the original TAM model described by Davis (1989). These were: disposition to trust and perceived trust. Disposition to trust describes a person's attitude or willingness to trust others and perceived trust indicates whether a person perceives a technological solution is secure and trustworthy or not. PriceWaterhouseCoopers (2003) in their survey describe trust as the "number 1 differentiator" (p. 8). Their findings suggest that trust empowered individuals to communicate and implement change in order to bring strategic aims to reality. They also suggest that innovators are connected by a sense of energy, curiosity and trust and that the role models required within organizations encourage, consider and trust rather than coerce, dismiss and control. 
Managers within IT organizations, to work effectively, need to provide a "heat shield" (p. 20) for innovators (MacMillan \& McGrath, 2004). This heat shield consists of a management matrix that encompasses recognition of opportunities, market entry and take-off, as well as venture capital, championing the innovation and moving the innovative product or service to market with appropriate speed. The PriceWaterhouseCoopers (2003) survey revealed that top innovative organizations have well-defined ideas of the management processes required to create a culture of innovation and an open management style. Goodman (2000) advocates a "people oriented, visionary approach" (p. 53) but believes that management's prime task should be to shape and co-ordinate employees' behavior so that the objectives of the organization can be achieved. Lapierre and Giroux (2003) describe how the fostering of creativity is a critical part of effective management.

McIntyre, Higgins and Couger (1993) and Amabile (1997) believe that both intrinsic and extrinsic motivation factors are important in supporting the development of creative ideas into final outcomes. Amabile identified that extrinsic motivators can take many forms, from the obvious factors such as rewards and recognition, though to factors such as having clearly defined goals and providing frequent constructive feedback. Amabile is of the opinion that although intrinsic factors provide greater motivation, enabling extrinsic motivators, such as additional technical resources, provide additional support to intrinsic motivators. The PriceWaterhouseCoopers (2003) survey found that carefully designed reward recognition systems to reinforce management behavior can provide both intrinsic and extrinsic motivational factors. The survey also pointed to the innovative success provided by a creativity improvement program, innovation being a priority at board level and the importance of an innovative culture within the organization.

Bean's (2002) Innovation Management Model recognizes the importance of the organizational culture for nurturing innovation. The other three important factors identified by Bean are: the capacity within the organization for innovation to occur; the ability to implement an innovation; and finally, the way that an innovation can be exploited and managed. Cooper (2000) suggests that organizational inertia typically inhibits organizational change and that managing IT development creativity is a complex process requiring understanding of both creativity and an ability to manage effectively in the face of organizational inertia. Peterson (2002), Dewett (2003) and Amabile (1997) stress the importance of positive feedback and encouragement as well as open and active communication within an organization to enhance creative flow within organizations. Patterson (2001) suggests that there are three important elements: a culture of innovation; a reliable infrastructure; and an integrated network with free-flowing linkages. Previous work by Amabile (1997) placed importance on the orientation of the organization towards wanting to take risks in order to move ahead of the marketplace; an appreciation of what employees are capable of achieving; and placing value on creativity and innovation.

Smaller organizations that are regarded as innovative appear to have less rigid management structures (Bartle, 2002). It is important to note that in New Zealand technical innovative activities are concentrated on Small and Medium Enterprises (SMEs) (less than 100 employees). Whilst large organizations have less flexible management structures they have a wider range of knowledge and staff skills available, can take better advantage of market growth and can spread the cost of innovation over a wider sales base. Boulding (1989) suggests that the ability to cope with rapid change is protection against vulnerability in any human activity system including innovative businesses. Davis-Havill (2004), in a study on growth and acceleration in SMEs, suggest that enhancing organizational culture is a prerequisite for developing sustainable growth in building new technological platforms. Cooper (2000), in studying creativity within information technology development, also stated that organizational inertia typically inhibits change resulting in IT developments that reflect the status quo. Resistance tactics included resistance delay, both externally from users and internally from within the organization from inflexible processes. 
Hogarth-Scott and Parkinson (1994), in considering barriers and stimuli of innovation in IT, suggest that there is a need for: (i) clear corporate strategy; (ii) strong IT leadership with continued support for new IT; (iii) strong user education; (iv) internal marketing; and (v) getting users involved in early product development.

Because findings from the literature suggest that it is difficult to have one definitive theory to explain patterns of creativity and innovation within an organization, it was decided to include in the first draft of the BIMM model (Fielden \& Malcolm, 2006) the core systems concepts of structure, control, communication and emergence (Checkland, 1984). Checkland describes structure as "those elements in a problem situation which are either permanent or change only slowly or occasionally" (p. 317). Control is described "as the process by means of which a whole entity retains its identity" (p. 313). Communication is described as "the transfer of information" (p. 313) and emergence as "properties of a whole entity that are only meaningful when attributed to the whole" (p. 314). It also appeared important to include the employee's role within the organization which may or may not be innovative. Freedom within an organization is often role dependent. An emphasis can be found in the literature on factors that contribute to incentives to innovate including motivation (Amabile, 1997; McIntyre et al., 1993) and culture (Bean, 2002; Cooper, 2000; Patterson, 2001; Peterson, 2002). Therefore incentives were included as a construct in BIMM. Finally it was deemed necessary to include "outcome" as the final construct capturing both "useful novelty" (p. 610) (Oldham \& Cummings, 1996) and purpose (Peterson, 2002).

The BIMM model emerging from the data gathered for this research, is based on core systems principles of communication, control, structure and emergence (Checkland, 1984) and on the fact that organizational systems, when considered as a whole, are bounded. Rules, regulations, mission statements, operational procedures and practices all provide organizational boundaries. As has been discovered by many researching in this field (Amabile, 1997; Bartle, 2002; Cheskin \& Fitch, 2003; Cooper, 2000; Cross \& Travaglione, 2003; Davis-Havill, 2004; Dewett, 2003; Fagan, 2004; Fichman, 2004; Jones \& Myers, 2001; Maloney, 2002; Marc Edwards, 2000; McIntyre et al., 1993; Patterson, 2001; PriceWaterhouseCoopers, 2003) capturing knowledge about the creative process is no easy task. In considering core systems concepts, rather than building on existing theoretical models of managing innovation and creativity, a different lens through which to study this complex phenomena has been provided in this paper. This model (which is currently in its second draft) we have called the Bounded Innovative Management Model (BIMM). The idea for the pictogram utilized in this model ( $D$ ) originated with the first author's doctoral dissertation (Fielden, 1995) where it was drawn to demonstrate a flexible, interacting innovation/creativity, osmotic link that oscillates about the bounds that are defined by system controls. The first draft of BIMM utilized this pictogram depiction and applied the model at the whole organization level (Fielden \& Malcolm, 2006). This is shown in Figure 1 where five different models were developed from interviews conducted with employees in upper management positions in five different organizations. In Figure 1a innovation is confined within the bounds provided from the mission statement through to day-to-day operational procedures. This is described as stifling creativity, where controlling mechanisms tend to overpower individual and collective innovative patterns. Figure 1a represents an organization in which innovation is only confined within organizational bounds. In such an organization, bounds are usually represented by business rules, financial constraints, organizational practices and procedures and strict adherence to only pursuing innovation that is aligned with organizational focus. Usually an innovation is required to be justified and approved within these bounds. Figure $1 \mathrm{~b}$ represents an organization in which innovation encloses the organizational bounds. In such an organization it is usual for innovations to "stretch" organizational bounds as business rules, practices and procedures are modified to accommodate and incorporate such innovation. Figure $1 \mathrm{~b}$ shows innovative patterns oscillating outside and around organizational bounds. The figure shows a "leaky" creative boundary which allows for influences to the creative process from outside of the organization. All other pattern maps pre- 
sented have solid boundaries indicating that the creative pattern is considered to be internal to the organization.

Figure 1c illustrates organizations in which innovation is offset but still partially contained by organizational bounds. Such an organization states that it welcomes new and innovative ideas regardless of organizational bounds, but when the innovator presents the innovation back to the company it is possible that such an innovation is not aligned with organizational direction. Such an innovative pattern may indicate a deeper misalignment within the organization. Figure 1c shows the innovative pattern displaced and still influenced by organizational bounds. This tends to be a problematic situation.

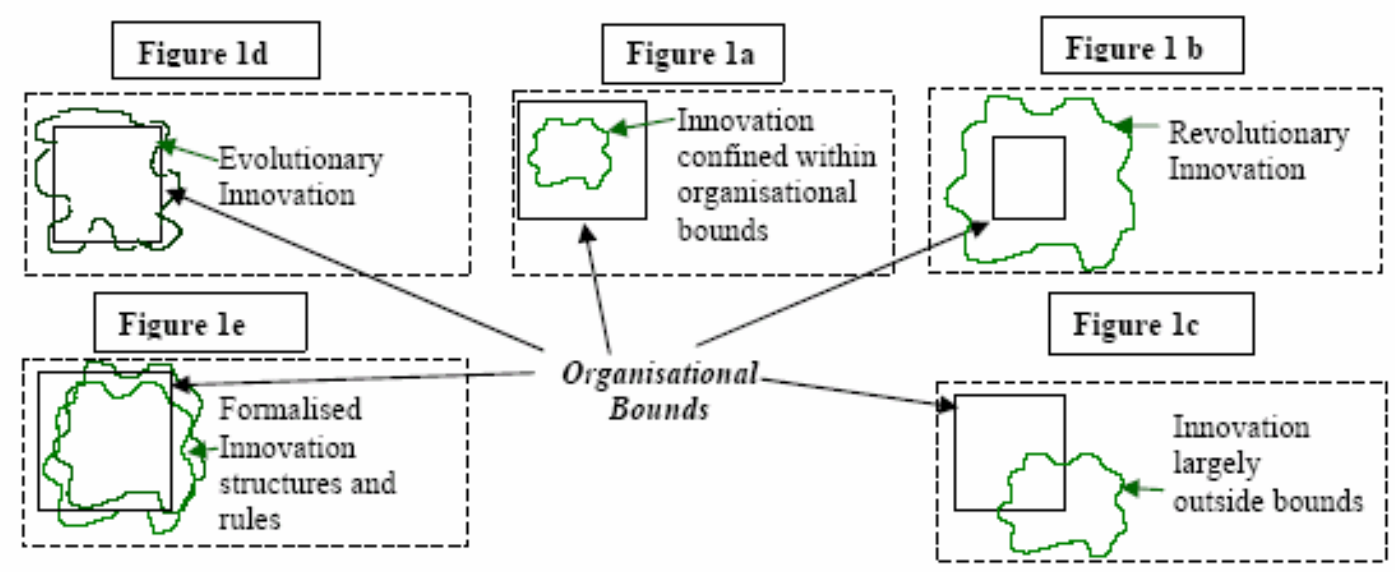

Figure 1: Bounded Innovation Management Model (Version 1)

Figure 1d demonstrates a classic innovative company in which innovation oscillates around organizational bounds. Innovation can happen both within organizational bounds and also outside of the bounds. It is important to note that such mappings show that synergies may exist between innovation and organizational bounds that are not fixed and may change to accommodate innovations adopted by the business. In Figure 1d the innovative pattern oscillates in direct relationship and alignment with the organizational bounds. This view tends to be held by managers, directors and leaders as a perception that may not be a reality. Figure 1e is a holistic view of the organization as opposed to viewing any one property or construct or adopting a single employee point of view. Figure 1e demonstrates the formalizing of innovative patterns in an endeavor to maximize the return on investment to reach final outcomes. Figure 1e indicates that there maybe multiple innovative patterns within an organization, as opposed to Figure 1d that shows a single innovative pattern mapping. Whilst only five mappings are shown, these are indicative only of many more such mappings. The theoretical position presented for the first draft of BIMM was that: (i) each person within an organization has at least one innovative or creative pattern mapping: (ii) this perceived creative pattern mapping may or may not be aligned with the actual organizational model of creative patterns provided within the organization; (iii) all innovative organizations hold at least one creative pattern mapping which may or may not be explicit; (iv) all creative patterns are influenced by organizational bounds; (v) barriers provided by tightly controlled bounds may stifle creative patterns; and (vi) creative pattern mappings out of alignment with organizational bounds may inhibit the development of creative ideas.

Many authors point to the need for further research to develop an understanding of how creative ideas become final outcomes (Fichman, 2004; Galliers \& Meadows, 2003; Glenn \& Gordon, 2000; Lapierre \& Giroux, 2003; Marc Edwards, 2000; McIntyre et al., 1993; Peterson, 2002). 
Fichman (2004) states that "the ultimate outcomes or benefits of innovation with IT are rarely considered in studies within the dominant paradigm" (p. 317). Fielden (2005) also believes that barriers to acceptance are situated within the traditional dominant paradigm and recommends mindset shifts generated by alternate thinking styles. Maloney (2002) also states that the factors that drive private sector innovative activity are poorly understood.

\section{Methodology}

The second draft of the theoretical model, (BIMM) (described below), which has been utilized as a theoretical framework for this study, emerged from a deep understanding of core systems principles described originally by Checkland (1984) and work completed in the first draft of BIMM (Fielden \& Malcolm,2006). These core principles are: communication, control, structure and emergence. Communication in organizations is generally considered to be communication between people which may or may not be assisted by technology. Control within an organization is usually provided by rules, regulations, mission statements, operational procedures and practices. Organizational structure is provided by reporting lines and duties within the organization. Emergence usually refers to those characteristics, properties, entities or events that surface when the system is considered as a whole. It is this last property of emergence that is most important to consider when researching creativity and innovation within an organization.

Organizational "space" is the arena in which business activities take place. Whilst it is possible for creativity or innovation to occur anywhere in an organizational "space", it appears from the data gathered that the norm is for innovation to be a bounded activity. Innovation appears to oscillate either within (Figure 1a), about (Figures 1d and 1e), or outside of organizational bounds (Figure 1b). When innovations occur across boundaries it appears to be an indicator for organizational misalignment (Figure 1c). Research is ongoing to test these possible scenarios. The pictograms emerged as a means of illustrating these various innovative scenarios.

The second draft of BIMM is the model that is utilized in this exploratory study. In this draft of BIMM the innovative pattern mappings are applied to the eight constructs (structure, communication, control, emergence, role, incentive, outcome and whole system). Pattern mapping is at the individual employee level. The pictograms at the individual construct level are shown in Figures 2 - 5. The BIMM model applied at this individual construct level provides an interpretative framework that enables an organization to understand more about innovative patterns and how to utilize these to the benefit of the business. All people within an organization tend to view the creative process differently. Indeed data gathered in this project tends to show that the participant interviewed tended to give information about individual perceptions of the creative process as well as information about the actual processes involved in mapping the patterns of innovation.

This paper uses a case-study methodology with in-depth interviews with the four employees of a small innovative software development company. The managing director has been with the organization for two years and has responsibility for ensuring sufficient funding is available to continue development. He also has overall project leadership and manages relationships with all key stakeholders. The software developer originated the innovative ideas that gave rise to the organization ten years ago. He describes his organizational activities as "developing and constructing innovative software". His present activities include: technical design; consulting with the academic adviser; and liaising with the University students who are assisting with implementation. His responsibilities are to ensure that technical construction operates correctly and is performed on time and provide theoretical proof for the software design ideas (architecture and proof of correctness). The joint venture officer has been employed for less than five years. His is an administrative role in which he makes sure that joint venture funds are spent wisely. His main responsibility is to maintain the joint venture contact database and to keep the joint venture partners fully informed of organisational activities. The sales and marketing officer has been involved with the 
organization for five years and lists as his main activities raising capital and product development. He is responsible for pursuing commercial opportunities for the products under development and for ensuring that capital requirement targets are met.

The analysis of interviews with each staff member is described in the Findings section.

In many organizations innovative processes are handled somewhat haphazardly. The authors were particularly interested in this small organization as its sole business was to develop and produce radically different software solutions. It was assumed that with only four employees there would be considerable alignment with

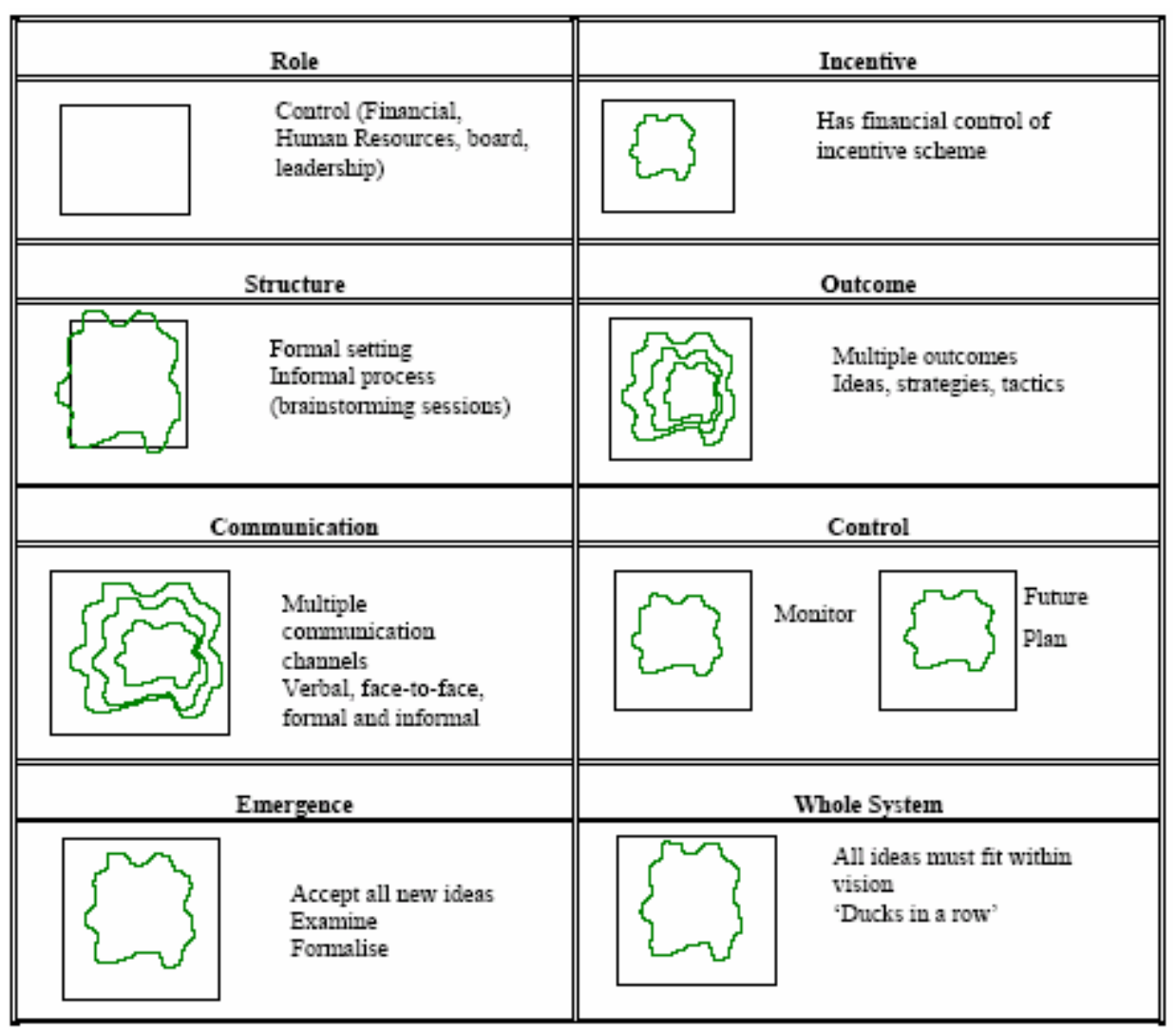

Figure 2 Managing Director Organization X perceptions towards innovation and how these patterns emerge in such a company. As the data analysis progressed it soon became apparent that this was not the case. Each employee demonstrated markedly different perceptions towards innovation (Figures 2-5).

The research questions for this case study were:

(i) What are the differing perceptions about the creative process of employees in a small software development company?; and

(ii) Are there different innovative pattern mappings for each employee?

This study aimed to validate the second draft of the BIMM model by mapping staff innovative patterns of a small software development company in Auckland, New Zealand.

The unit of analysis for this case study was the individual employee within the organization. Data about individual perceptions of how innovative patterns manifested within the company were collected.

Data was gathered from: (i) semi-structured interviews conducted with all four employees; (ii) company documents; and (iii) in-depth knowledge of the company gleaned from one of the author's relationship with the organization as an academic adviser for the past four years. 
In the first part of the interview, demographic data about the organization and organizational roles were gathered. The second part of the interview was focussed on discovering how the organization managed innovation and creativity including: incentives in place to encourage the sharing of new ideas; role within in the organization in providing incentives; organizational structures to nurture new ideas; transformation of new ideas into final outcomes or processes; organizational communication patterns for new ideas; monitoring of the development of new ideas to final outcomes; and organizational responses to emergent ideas.

The responses obtained from each interview were analysed according to the eight constructs of BIMM. Each construct became the coding category for the analysis. Each participant was coded individually so that a "whole system"

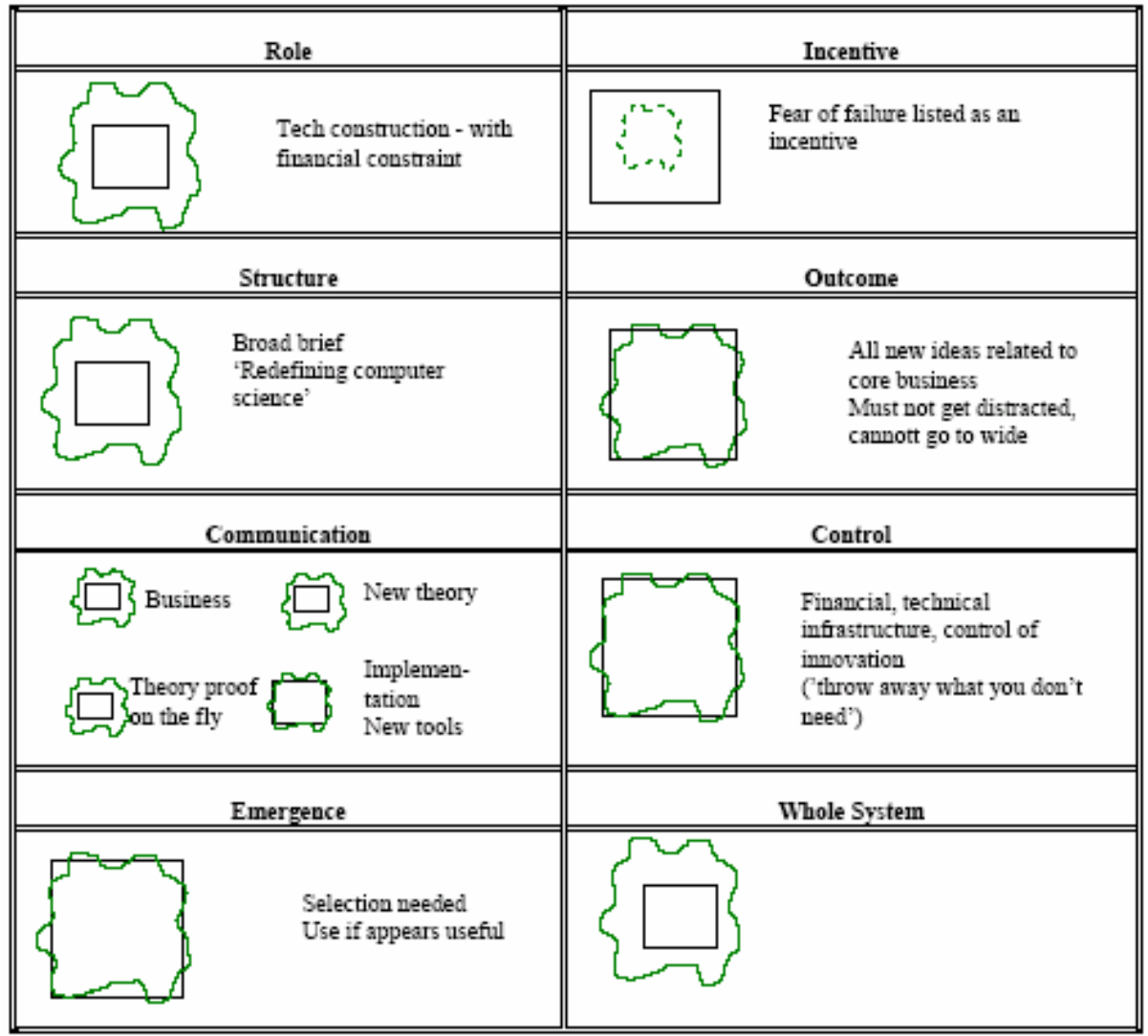

Figure 3 Software Developer Organization X

response could be aggregated for each participant. The constructs; role, incentive and structure were relatively straightforward as the responses given needed little interpretation. Deriving the communication category was not as straightforward as a complete individual interview transcript needed to be scanned to elicit a response for this category. It can be seen, for instance, from Figure 3 that the software developer gave multiple responses for communication and these were given at different stages of the interview. The construct "outcome" was not pre-defined for the participants. This meant that each participant responded from his own point of view. This is highlighted in the different views of what "outcomes" were for each participant (Table 1). The managing director believed that ideas, strategies and tactics were all final outcomes. The software developer believed that any innovative idea needed to be related to core business. The software developer was also aware of his own propensity to become distracted by new ideas that arose from outside the bounds of core business. The sales and marketing officer concentrated his response on products, licensing and financial ratings as outcomes and the unspecific nature of the joint venture officer's response suggested that this was not something that he though much about. The control construct was coupled closely with each participant's role within the organization. Included in the managing director's role was monitoring of the other employees' performance. The software developer was most aware of financial controls. The other two employees both suggested that performance reviews and assessment were control devices. For the constructs emer- 
gence and "whole system" it was essential to consider the whole interview for each participant both individually and collectively. Whilst this "muddies the waters" as far as the unit of analysis is concerned, this is indeed what happened. Each employee agreed that any new ideas emerging anywhere in the organization needed to be discussed collectively. The "whole system" responses reflected individual views of the business as a whole. The managing director discussed his "ducks in a row" in his response because to him it was important to align innovative activities. The software developer believed that technical innovation happened outside of organizational bounds. The joint venture officer did not provide a response to this question and the sales and marketing officer reverted to his response that "everyone was encouraged to come up with new ideas" (Table 1).

The reporting of the case study is largely in a narrative format that allows the reader to "vicariously experience these happenings and draw conclusions (which may differ from the researcher)" (Stake 2000, p. 439). Donmoyer (1998) suggests that by being presented with "medium-rare" data the reader, without actually being there, has accessibility to experiences and the option of being able to interpret the information presented by the researcher. His term "medium-rare" data is explained as being data beyond uncontaminated raw data, but containing a relatively small degree of interpretation with excerpts from transcribed interviews.

\section{Findings}

The responses for each employee on their individual innovative pattern mapping innovative were captured according to the eight BIMM constructs - role, incentive, structure, outcome, communication, control, emergence and whole system. These are described below.

\section{Structure}

All four memmembers of Organization X were interviewed and all had different views on what innovative patterns were. The managing director regarded the weekly brainstorming sessions as an essential structural element in nurturing the development of new ideas. He also believed that the key incentive for his staff was participant in-

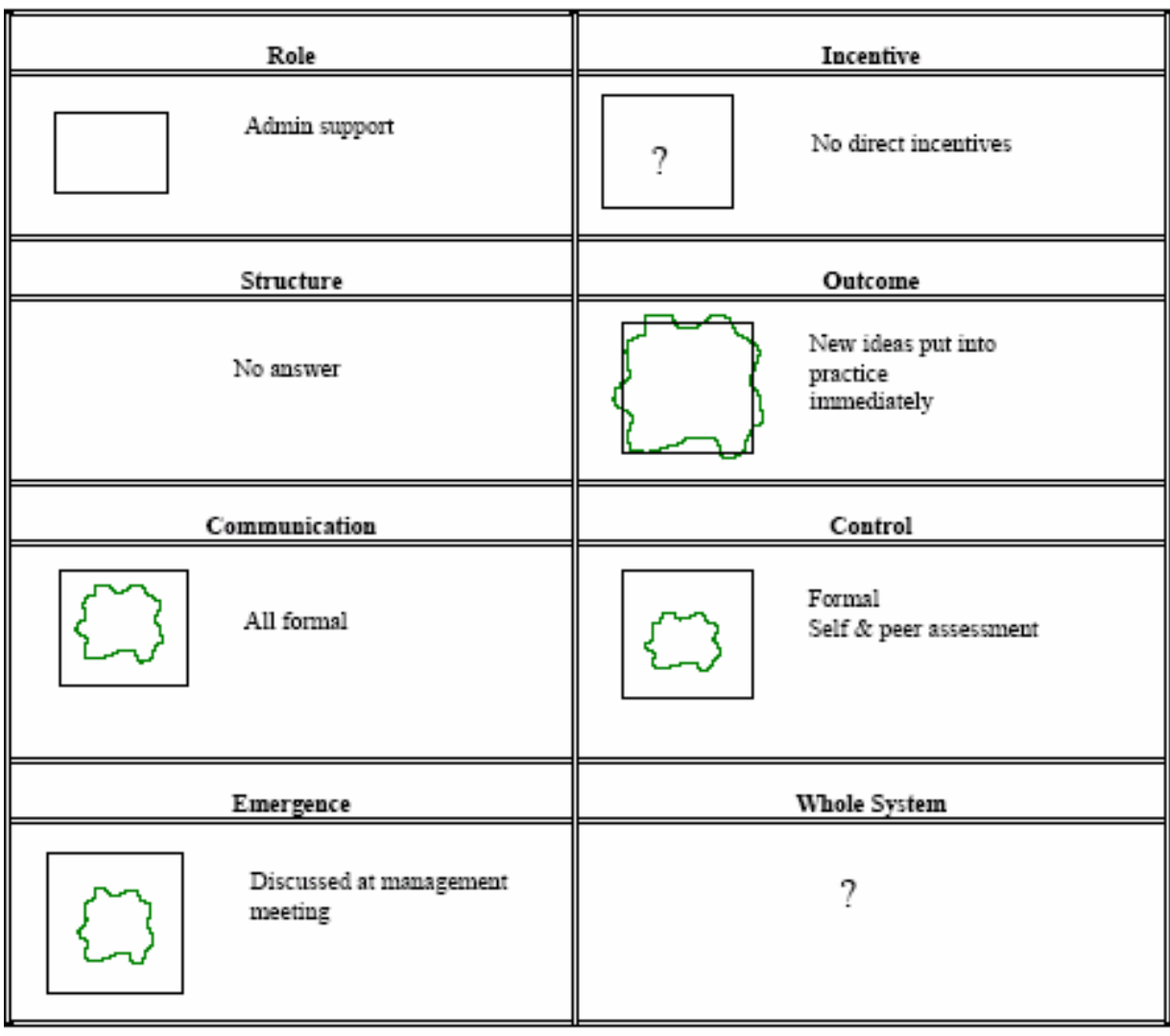

Figure 4 Joint Venture Partner Officer Organization X 


\begin{abstract}
volvement in
the

ownership of

the venture

(the

organization

is operating

as a joint-

venture part-

nership).

There were

formal

structures in

place to

monitor and

control

innovation

within the

company -

project plans,

milestones

and monthly

monitoring.
\end{abstract}

The software developer

stated that he had a broad brief. He could be innovative as long as the company moved forward.

In Figure 3 the software developer's level of innovation is represented as radical innovation "outside the square".

The joint venture officer was the most distant from the daily innovation required within the organization. Although he attended the weekly brainstorming sessions he did not see these as a structural element to support innovation. Structure for him was provided by maintaining the joint venture database which had little to do with the development of new ideas for innovative software. This is represented in Figure 4 as no creative pattern.

The sales and marketing officer also mentioned the weekly brainstorming sessions as a structural element in the development of new ideas. This is represented in Figure 5 as innovation within organization bounds.

\title{
Communication of New Ideas within the Organization
}

The staff within Organization X believed in keeping the communication within the organization as open as possible, using whatever form of communication was most appropriate whether it was verbal, written or face-to-face. There were formal reporting requirements and monthly management meetings (with formal minutes circulated to all relevant parties). The managing director recognized that there were multiple communication channels for innovation to happen and this is represented in Figure 2.

The software developer however, because he was dealing with innovation "at the sharp end", was required often to develop solutions "on the fly" as technical problems arose. These were communicated on a "need to know" basis as they happened. It is interesting to note that the software developer recognized that different communication patterns occurred within the organization de- 
pending on whether it was about the business, about software development, communication with stakeholders or implementation of new tools (Figure 3). The sales and marketing officer stated that after the weekly brainstorming sessions, someone within the organization was appointed to research and write up the new idea which was subsequently considered at executive level where a decision would be made on its implementation. This is represented as formal communication "within the square" (Figure 5).

\section{Control Mechanisms}

The managing director of Organization $\mathrm{X}$ had formal structures in place to monitor and control innovation within the company - project plans, milestones and monthly monitoring (Figure 2). The software developer stated that because the organization was economically driven and because they had not yet generated a revenue stream it was essential to innovate with strict financial controls (Figure 3). Any new software design ideas needed to fit within the overall holistic problem definition and that he could not afford to go off on any tangents no matter how alluring they may appear. The sales and marketing officer stated that all innovative ideas were measured against current objectives for the company (Figure 5).

\section{Emergence}

The managing director was very conscious of the need to examine every new idea emerging. If the new idea turned out to be of potential value to the business, the innovation would be formalized into implementation phases and procedures immediately (Figure 2). The software developer believed that emergent ideas were debated by the management committee and selected if appropriate (Figure 3). The joint venture partner officer concurred with this statement (Figure 4).

\section{Tracking Innovative Patterns}

The managing director realized that whilst fostering an environment for idea generation, one must always ensure they fit into the overall vision and strategy that is in place to deliver this vision (Figure 2). The software developer stated that his job was "pure innovation". This is represented as creativity "outside the square" (Figure 3 ). He said that he could not "consult books" and that "there was no road map", that he invented as he needed new ideas products or outcomes. He believed that there was an empty space out there and the organization was hurtling towards a final outcome.

\section{Incentives to Share New Ideas}

Within Organization X there were four different views of what incentives were in place. The managing director believed that the key incentive was participant involvement in the ownership of the venture (the organization is operating as a joint-venture partnership) (Figure 2). The software developer also believed that the stock incentive was important and that the time-to-market rather than the ideas being generated, kept the company afloat. A negative factor that provided impetus for him, in particular, was fear of failure that may cause the company to collapse (Figure 3 ). The joint venture partner officer and the sales and marketing officer on the other hand could see no direct incentives (Figures 4 and 5).

\section{Transformation of New Ideas into Final Outcomes}

Because Organization $\mathrm{X}$ is in the business of innovative software development transformation of new ideas into final outcomes, all employees believed that this was their core business. The managing director particularly stressed the need to stay focused and that their business processes needed to be disciplined in order to reach final production (Figure 2). 


\section{Outcomes}

The managing director of Organization X stated that outcomes included ideas, strategies, and tactics to ensure final outcomes (Figure 2). He believed that the timely order of doing things was important. He liked to get "all the ducks in a row". In a small organization where resources were limited he believed that this was important. The software developer believed that the whole business was an outcome of how new ideas were transformed (Figure 3). The joint venture partner officer concentrated on outcomes relating to information circulation to both joint venture partners and potential customers (Figure 4).

\section{Findings Summary}

In the summary table (Table 1) it can be seen that there are many difference innovative patterns displayed for each employee. These are discussed below.

\section{Discussion}

The definitions of creativity, from the literature studied, that impact on the IT industry in tracing innovative patterns are (i) ill-defined problem situations; (ii) recombination of existing factors for innovation; (iii) radical newness (and the industry acceptance of this); (iv) the products of creative endeavors must have value; and (v) creativity is a bounded activity. In Organization X, all of these factors were present, particularly radical newness. Organization $\mathrm{X}$ is developing a radically new approach to secure digital business. This is consistent with Jones and Myers' (2001) definition of an innovation as being an idea, practice or object that is perceived as new.

Lapierre and Giroux (2003), Hogarth-Scott and Parkinson (1994) and PriceWaterhouseCooper (2003) stress the importance of committed and strong management in an innovative organization. The managing director of Organization X combined vision, strategy and control in such a way to maximize return on innovations produced. Managing the innovative process was vital and understood extremely well by the managing director. He continues to support and nurture a culture of innovation with reliable infrastructure

While trust has been identified in the literature as a very important factor for innovation to occur, in our study trust was not mentioned explicitly as a factor. However, insights into how the organization functions, gained by one of the authors over the last five years in consulting with the company, suggest that trust does exist. Roles within the organization are clearly defined and all staff members "trusted" that the software developer could produce the innovations required to "get to market".

Multiple factors have been identified as being necessary for innovation to occur. In the organization studied it appeared that there was a complex balance of factors including clear corporate strategy; strong IT leadership with continued support for new IT; strong user education; and internal marketing. Motivation within the organization studied was highest for the software developer who was the innovator and whose creative ideas were being produced. The software developer was certainly passionate about what he produces, clearly intrinsically motivated and appreciated the organizational structure and management style that allowed him to "get on with the job of innovating". Resistance tactics (Cooper, 2000), such as resistance delay from external users and internally from inflexible processes, were not apparent within this organization. The managing director of this organization combined vision, strategy and control in such a way to maximize return on innovations produced.

Hogarth-Scott and Parkinson (1994) in considering barriers and stimuli of innovation in IT suggest that there is a need for: (i) clear corporate strategy; (ii) strong IT leadership with continued support for new IT; (iii) strong user education; (iv) internal marketing; and (v) getting users in- 
volved in early product development. All of these components appeared to be present within the organization studied except for user involvement. Amabile (1997), Bartle (2002) and Boulding (1989) discussed why it is necessary for an organization to take risks, move outside the organizational boundaries and cope with rapid change if the organization wanted to move ahead in the marketplace. The two innovators (software developer and managing director) at Organization X, agreed with these sentiments. Amabile (1997) and McIntyre, Higgins and Couger (1993) identified the intrinsic and extrinsic motivational factors necessary for innovation to occur. Motivation within the organization studied was highest for the software developer. He is the innovator whose creative ideas are being produced. He was certainly passionate about what he is producing, clearly intrinsically motivated and appreciated the organizational structure and management style that allowed him to "get on with the job of innovating".

BIMM has been a useful tool to show how widely different the perceptions of creative patterns can be within an organization. Model formation is also advocated by Bean (2002) who advocates for the use of a theoretical model to assist with a clearer understanding of how innovation functions. Any individual employee may view each one of the eight constructs within BIMM with a different innovative pat-

\begin{tabular}{|c|c|c|c|c|}
\hline & $\begin{array}{l}\text { Managing } \\
\text { Director }\end{array}$ & $\begin{array}{l}\text { Software } \\
\text { Developer }\end{array}$ & $\begin{array}{l}\text { Joint Venture } \\
\text { Officer }\end{array}$ & $\begin{array}{l}\text { Sales \& } \\
\text { Marketing }\end{array}$ \\
\hline Role & $\begin{array}{l}\text { Control } \\
\text { Human Resources } \\
\text { Board } \\
\text { Leadership } \\
\end{array}$ & Technical construction & $\begin{array}{l}\text { Administration } \\
\text { support }\end{array}$ & Financial \\
\hline Incentive & Financial & $\begin{array}{l}\text { Fear of failure listed as } \\
\text { an incentive }\end{array}$ & No direct incentive & No incentive \\
\hline Structure & $\begin{array}{l}\text { Formal setting } \\
\text { Informal process } \\
\text { (brainstoming) }\end{array}$ & $\begin{array}{l}\text { 'Broad brief' } \\
\text { 'Redefining computer } \\
\text { science' }\end{array}$ & No answer given & $\begin{array}{l}\text { Brainstoming } \\
\text { sessions }\end{array}$ \\
\hline $\begin{array}{l}\text { Transform- } \\
\text { ation }\end{array}$ & Core business & Core business & Not mentioned & Not mentioned \\
\hline Outcome & $\begin{array}{l}\text { Multiple outcomes } \\
\text { Ideas Strategies } \\
\text { Tactics }\end{array}$ & $\begin{array}{l}\text { All new ideas related to } \\
\text { core business Must not } \\
\text { get distracted Cannot go } \\
\text { to wide }\end{array}$ & $\begin{array}{l}\text { New ideas put into } \\
\text { practice } \\
\text { immediately }\end{array}$ & $\begin{array}{l}\text { Product } \\
\text { License Financial } \\
\text { rating }\end{array}$ \\
\hline $\begin{array}{l}\text { Communicat- } \\
\text { ion }\end{array}$ & $\begin{array}{l}\text { Multiple } \\
\text { communication } \\
\text { channels - verbal, } \\
\text { face-to-face, formal } \\
\text { \& informal }\end{array}$ & $\begin{array}{l}\text { Communication about } \\
\text { imnovation outside } \\
\text { organization bounds for } \\
\text { business, new theory, } \\
\text { new proofs Around } \\
\text { organizational bounds } \\
\text { for } \\
\text { implementation and } \\
\text { development of new } \\
\text { tools }\end{array}$ & $\begin{array}{l}\text { All within } \\
\text { organisational } \\
\text { bounds and form }\end{array}$ & $\begin{array}{l}\text { Brainstorming } \\
\text { formalised and sent } \\
\text { to management }\end{array}$ \\
\hline Control & $\begin{array}{l}\text { Present - monitor } \\
\text { Future - plan }\end{array}$ & $\begin{array}{l}\text { Financial limits } \\
\text { Control of imnovation - } \\
\text { 'throw away what you } \\
\text { do not need' }\end{array}$ & $\begin{array}{l}\text { Formal } \\
\text { Self and peer } \\
\text { assessment }\end{array}$ & $\begin{array}{l}\text { All ideas measured } \\
\text { against objectives }\end{array}$ \\
\hline Emergence & $\begin{array}{l}\text { Accept all new } \\
\text { ideas Examine } \\
\text { Formalise }\end{array}$ & $\begin{array}{l}\text { Selection needed Use if } \\
\text { appears useful }\end{array}$ & $\begin{array}{l}\text { Discussed at } \\
\text { management } \\
\text { meeting }\end{array}$ & $\begin{array}{l}\text { All new ideas fed } \\
\text { into next } \\
\text { brainstorming } \\
\text { session }\end{array}$ \\
\hline $\begin{array}{l}\text { Whole } \\
\text { System }\end{array}$ & $\begin{array}{l}\text { All ideas must fit } \\
\text { within vision } \\
\text { "Ducks in a Row" }\end{array}$ & $\begin{array}{l}\text { Innovation happens } \\
\text { outside organization } \\
\text { bounds }\end{array}$ & No answer given & $\begin{array}{l}\text { Everyone } \\
\text { encouraged to } \\
\text { come up with new } \\
\text { ideas }\end{array}$ \\
\hline
\end{tabular}

Table 1 Participant Responses

tern mapping, or indeed multiple patterns. This was the case for the software developer in his views on how innovative ideas were communicated within the organization. The software developer also differentiated between innovative pattern mappings for communicating new technical ideas which he saw as oscillating outside of organizational bounds, and the implementation of new tools which was depicted as oscillating about organizational bounds. It became clear as the data was analyzed that the joint venture officer did not perceive his role as one that provided 
freedom to innovate. It was surprising to both the researchers and the organization that the sales and marketing officer believe that innovative patterns were clearly contained within organizational bounds. In this study two of the participants - the managing director and the software developer - demonstrated high levels of innovative pattern awareness in their responses whilst the other two employees showed much lower awareness of innovative patterns. Using BIMM to analyze innovative patterns within Organization $\mathrm{X}$ has provided the managing director with deeper insights into the varied nature of employee perceptions of innovative patterns and has provided him with more management tools. In many ways this analysis did not impinge on the way in which the software developer operates within the organization. His role is to generate and implement new technical concepts. This is where his creativity is directed rather than managing an innovative business. BIMM has helped to differentiate between innovation in management and software development.

\section{Conclusion}

Further research is required to validate the bounded innovation management model. One small innovative software development organization of four employees does not provide sufficient information to validate the model. At this stage the research is exploratory and the fact that the company chosen for this small case study was a software organization means that the findings do not necessarily apply to other types of information technology businesses. It is inappropriate to apply these findings to any other type of software organization at this stage. Results may not apply to an organization that does have innovation as a central theme within its mission statement. Whilst there are many limitations to this study the authors believe that the BIMM model developed is appropriate for use within an IT organization that has innovation at the core of its business processes. Organization X has been built around a fundamental shift in the way in which software is developed and brought to market. For this reason alone it was an ideal company to test the BIMM model. Application of the model to larger IT companies is an area for further research. Five organizations including a large multinational software business are all targets for future research. All of these organizations are committed to innovation as a central strategic direction for their activities. It would be interesting to explore whether introducing the BIMM model to an organization could trigger a greater awareness of existing innovative patterns that may help business rules and processes to operate more effectively.

Using an interpretive tool such as BIMM at a whole systems level, as well as the individual employee level within this particular organization for the constructs chosen (structure, communication, control, emergence, role, incentive, outcome and whole system), has the potential to uncover a richness of innovative pattern mappings that may have been unnoticed when an organization is viewed as a whole system. Often the assumption is that employees will be aligned in their perceptions about the impact that innovations have for the organization. Our study has shown that in one small software development business, which described its activities as "pure innovation", that each employee does not view innovative pattern mappings in the same way. Within this case study there were only two out of four of the employees who demonstrated an acceptance of innovation and the importance of mapping innovative patterns within organizational activities. Each employee had both clearly defined views and roles within the organization and also overlapping and disparate views of how the business conducted these "pure innovation" activities. The managing director's overlapping roles included boundary enforcement, auditing and control as well as a supportive and flexible environment in which innovations could proceed. He recognized the importance of multiple innovative pattern mappings and the need for alignment of multiple patterns which he describes as "ducks in a row". The software developer viewed the technical activities as where the "pure innovation" was occurring. He described this as software development with "no roadmap". A constant tension was in aligning with organizational aims whilst producing 
innovative software for which there were no existing guidelines. Whilst the other employees recognized that this was the heart of the business they did not view their roles as innovative.

BIMM appears to reflect the views being expressed in the literature on innovation management and the model shows clearly what innovative pattern mappings exist within an organization and how these pattern mappings are managed. Relating innovation concepts to core systems properties has enabled a different view of the management of innovative pattern mappings within organizations.

\section{References}

Amabile, T. M. (1997). Motivating creativity in organizations: On doing what you love and loving what you do. California Management Review, 40(1), 39-58.

Bartle, D. (2002). Insights of NZ innovation experience from evaluations of technology-grant programmes and empirical studies. Wellington, NZ: Foundation for Research Science and Technology.

Bean, R. (2002). The business of innovation: Managing the corporate imagination for maximum results. New York: AMACOM.

Boulding, K. (1989). Towards a theory of vulnerability. Journal of Applied Systems Analysis, 16, 1-17.

Checkland, P. (1984). Systems thinking, systems practice. Great Britain: John Wiley \& Sons Ltd.

Checkland, P., \& Scholes, J. (1990). Soft systems methodology in action. Chichester: Wiley.

Cheskin, \& Fitch. (2003). Fast, focused \& fertile: the innovation evolution: A look at the changing nature of innovation.

Cooper, R. B. (2000). Information technology development creativity: A case study of attempted radical change. $M I S Q, 34(2), 245-276$.

Cross, B., \& Travaglione, A. (2003). The untold story: Is the entrepreneur of the 21 st century defined by emotional intelligence? International Journal of Organizational Analysis, 11(3), 221-228.

Dahlberg, T., Mallat, N., \& Oorni, A. (2003). Trust-enhanced technology acceptance model-Consumer acceptance of mobile payment solutions. Paper presented at the CIC Roundtable.

Davis, F. (1989). Perceived usefulness, perceived ease of use, and user acceptance of information technology. MIS Quarterly, 13(3), 318-340.

Davis-Havill, M. (2004). A growth and innovation acceleration process for small \& medium enterprises. Hamilton, NZ: Waikato Management School.

Dewett, T. (2003). Understanding the relationship between information technology and creativity in organizations. Creativity Research Journal, 15(2), 167-182.

Donmoyer, R. (1998). Generalizability and the single case-study. In E. W. Eisner \& A. Peshkin (Eds.), Qualitative inquiry in education. The continuing debate (pp. 175 - 200). New York: Teachers College Press.

Fagan, M. H. (2004). The influence of creative style and climate on software development team creativity: An exploratory study. Journal of Computer Information Systems, Spring, 73-80.

Fichman, R. (2004). Going beyond the dominant paradigm for information technology innovation research: Emerging concepts and methods. Journal of the Association of Information Systems, 5(8), 314-355.

Fielden, K. (1995). Extending human potential in a technical learning environment. Unpublished PhD, University of Western Sydney.

Fielden, K. (2005). Mindfulness: An essential quality of integrated of wisdom. In J. Courtney, J. Haynes \& D. Paradice (Eds.), Inquiring organizations: Moving from knowledge management to wisdom (pp. 271300). Hershey, USA: Idea Books. 
Fielden, K., \& Malcolm, P. (2006, July). Organisational pathways: Creativity to productivity. Paper submitted to European Conference on Information Systems 2006.

Galliers, R., \& Meadows, M. (2003). A discipline divided: Globalization and parochialism in information systems research. Communications of the Association for Information Systems, 11, 108-117.

Glenn, J., \& Gordon, T. (2000, January 19-21). Views from the millennium project on the future of technology: On the threshold: The United Nations and global governance in the new millennium. Paper presented at the On the Threshold: The United Nations and Global Governance in the New Millennium,.

Goodman, M. (2000). The frustration of talent: A study in scarlet. Creativity \& Innovation Management, 9(1), 46-53.

Hogarth-Scott, S., \& Parkinson, S. (1994). Barriers and stimuli to the use of information technology in retailing. Routledge, 4(3), 257-275.

Houtz, J. C., Selby, E., Esquivel, G. B., Okoye, R. A., Peters, K. M., \& Treffiger, D. J. (2003). Creativity styles and personal type. Creativity Research Journal, 15(4), 321-330.

Isaksen, S. G., \& Lauer, K. J. (2003). An examination of the relationship between personality type and cognitive style. Creativity Research Journal, 15(4), 343-354.

Jones, N. D., \& Myers, M. D. (2001). Assessing three theories of information systems innovation: An Interpretive case study of a funds management company. AMCIS2001, 1005-1019.

Kelly, S. (1999). What business can learn from a simple science of complexity. The Journal of Quality Participation, 22(5), 221-224.

Lapierre, J., \& Giroux, V.-P. (2003). Creativity and work environment in a high-tech context. Creativity \& Innovation Management, 12(1), 11-23.

Lu, J., Liu, C., Yu, C.-S., \& Yao, J. E. (2002). Exploring factors associated with wireless internet via mobile technology acceptance in mainland China. Communications of the International Management Association, 3(1), 101-120.

MacMillan, I. C., \& McGrath, R. G. (2004). Nine new roles for technology managers. Research Technology Management, May-June, 16-26.

Maloney, W. F. (2002). Global patterns of innovative effort. Paper presented at the Workshop on Productivity, Performance, Prospects and Policies, Wellington, NZ, July 28-29.

Marc Edwards, S. (2000). The technology paradox: Efficiency versus creativity. Creativity Research Journal, 13(2), 221-228.

Maturana, H., \& Varela, F. (1998). The tree of knowledge: The biological roots of human understanding. USA: Shambala.

McIntyre, S. C., Higgins, L. F., \& Couger, J. (1993). (Un)structured creativity in information systems organizations. MIS Quarterly, 17(4), 375-398.

Oldham, G., \& Cummings, A. (1996). Employee creativity: Personal and contextual factors. Academy of Management Journal, 39(3), 607-635.

Ornstein, R. (1991). The evolution of consciousness: The origin of the way we think. New York: Simon \& Schuster Inc.

Patterson, E. (2001). Innovation and creativity: Bringing it all together. Retrieved from http://www.knowledgewave.org.nz/conference_2001/documents/Innovation\%20and\%20Creativity.pdf

Peterson, R. (2002). Establishing the creative environment in technology education. The Technology Teacher, December/January, 7-10.

PriceWaterhouseCoopers. (2003). Innovation survey. London: Price Waterhouse and Coopers \& Lybrand.

Research, B. M. S. (2003). Business trends survey 2003. Auckland: NZIM. 
Rogers, E. (1995). Diffusion of innovation (4th ed.). New York: Free Press.

Stake, R. (2000). Case studies. In N. Denzin \& Y. Lincoln (Eds.), Handbook of qualitative research (pp. 435-454). California: Sage.

\section{Appendix}

\section{Interview Questions}

\section{Software Development Industry New Zealand} Innovative Patterns Interview Questions

$\begin{array}{lllll}\text { Age } & 20-30 & 31-40 & 41-50 & >50 \text { (circle one) } \\ \text { Gender } & \mathrm{M} & \mathrm{F} \text { (circle one) } & \\ \text { Ethnicity } & \text { Pakeha } & \text { Maori } & \text { Indian } & \text { Chinese (circle one) } \\ & \text { Pacific Islander } & \text { Other (please state) } & \end{array}$

For what organisation do you work?

How does your organisation classify itself? (Circle one)

Small Medium Large Education Industry Development

How many years have you been employed by this organisation? (Circle one)

$\begin{array}{llll}0-5 & 6-10 & 11-20 & >20\end{array}$

What roles have you had within this organisation? (Circle all that apply)

Management

Software Developer

Analyst Engineer

Administrator

Sales

Finance Educator/Trainer

Other (please state)

How long have you been in these roles?

How would you describe what your organisation does?

What are the main activities that you perform within the organisation in your current position?

What are your responsibilities?

What incentives are in place in your organisation to encourage the sharing of new ideas? 
What is your role in any incentive scheme?

What structures are in place in your organisation to nurture new ideas?

Are new ideas transformed into outcomes or processes?

If so what are these outcomes or processes?

How is the process from new ideas to final outcomes communicated in your organisation?

What controls are in place to monitor the development of new ideas to final outcomes?

How does your organisation respond to new ideas that seem to spring up out of nowhere?

Do you have any other comments? 


\section{Biographies}

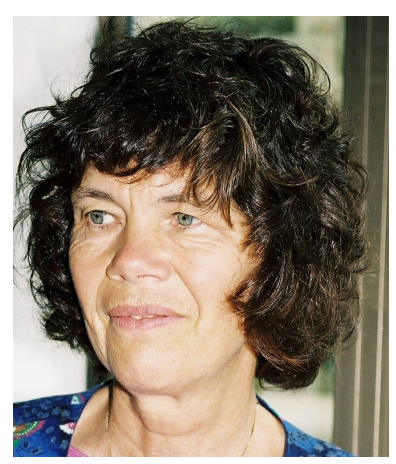

Dr Kay Fielden is an associate professor in Computing in the School of Computing and Information Technology, Unitec Institute of Technology, Auckland, New Zealand. She is also the research leader for the school, mentors staff research, supervises postgraduate students and teaches postgraduate research methods. Her own research interests are grounded in qualitative research and systems thinking.

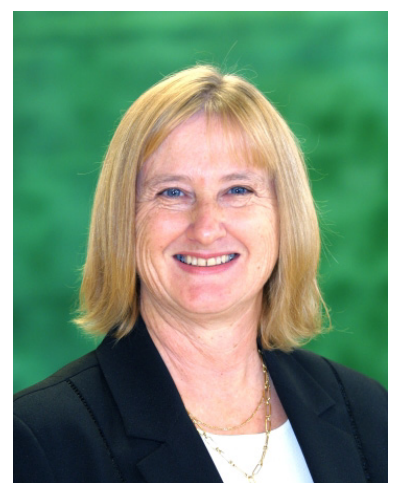

Pam Malcolm is a senior lecturer and associate head of school in the School of Accountancy Law and Finance at Unitec Institute of Technology, Auckland, New Zealand. Pam holds a Masters in Computing and has taught Accounting Information Systems for many years. She has a strong interest in researching online learning and social aspects of information systems. Pam is also a member of the NZ Institute of Chartered Accountants Accounting Technician College. 